\title{
Attracting College and High School Students to Study Engineering Technol- ogy through Hands-on Mechatronics Product Design Projects
}

\section{Dr. Andy S Zhang, New York City College of Technology}

Dr. Andy S. Zhang earned his master's in Mechanical Engineering from the City College of New York in 1987 and his Ph.D. in Mechanical Engineering from the Graduate Center of the City University of New York in 1995. Prior to joining the Mechanical Engineering Technology Department at City Tech, he served as an engineering instructor for the JUMP, an engineering training program sponsored by the New York State Department of Transportation. Dr. Zhang's research area includes materials testing, composite materials, $\mathrm{CAD} / \mathrm{CAE}$, engineering animation, and mechatronics.

\section{Dr. Sidi Berri, New York City College of Technology \\ Dr. Iem H Heng, New York City College of Technology}

Dr. Iem Heng earned his bachelor's degree from Providence College in Providence, RI with double majors in the Pre-Engineering Program and Mathematics. In addition, he earned another bachelor's degree from Columbia University in New York in Mechanical Engineering and a master's in Applied Mathematics from Western Michigan University at Kalamazoo, MI; his Ph.D. in Computational and Applied Mathematics from Old Dominion University at Norfolk, Va. Before joining the EMT/CET Department at City Tech in fall 2007, he was a faculty member and chair of the CET Department at DeVry Institute of Technology at Long Island City, NY. He worked as a researcher for NASA Langley Base in Hampton, Va., for two years. His research activities include embedded systems, robotics, mechatronics, software development for embedded systems with real time simulation, real time gaming simulation programming, and web application programming.

\section{Dr. Farrukh Zia, New York City College of Technology CUNY}




\title{
Attracting College and High School Students to Study Engineering Technology through Hands-on Mechatronics Product Design Projects
}

\begin{abstract}
This poster presents the work on using hands-on mechatronics design activities to attract college, as well as high school students, to study engineering technology. This work is supported by a grant from National Science Foundation (NSF) Advanced Technology Education (ATE) division. The Mechatronics Technology Center (MTC) established by the grant enables faculty members from different engineering technology fields to collaborate to introduce mechatronics technology to college students through multidisciplinary hands-on design projects, enable students from mechanical engineering technology, computer engineering technology, electrical engineering technology, industrial design technology, computer system technology to work together to engage in various hands-on undergraduate research projects, enable the college to reach out to high school students from more than 30 local high schools who have interest in engineering through hands-on robotic design projects. These hands-on activities exposed the latest mechatronics technology to the students and at the same time encourage the students to study engineering technology. Engineering technology encompasses many engineering technology fields: mechanical engineering technology, electrical engineering technology, and computer engineering technology, etc. Our integrated hands-on approach in introducing the multidisciplinary design projects to students, make them to realize the intrinsic relations among the four STEM fields and their interdependency.
\end{abstract}

\section{Introduction}

Engineering technology education has always been a key in producing college graduates to work in today's fast paced, highly competitive public and private enterprises. Unfortunately, the supply of qualified workforce has been reduced in the United States due to the steady drop of enrollment of college and high school students in STEM related fields for the past twenty years. To tackle the dwindling enrollment of STEM students and low quality of STEM graduates, the National Science Board submitted a report to Congress in 2007 suggesting all students need to develop their capabilities in STEM to levels much beyond what was considered acceptable in the past with an increased emphasis on technology and engineering at all levels in the Nation's education system. The Board gave two priority recommendations: (1) Ensure Coherence in Nation's STEM Education System; (2) Ensure that Students Are Taught by Well-Prepared and Highly Effective STEM Teachers [1]. This poster aims at addressing the two issues that many educational institutions are facing through the introduction of mechatronics technology into undergraduate students as well as to high school students.

To change the landscape of technology education in the US, many things must be done. Hands-on engaging activities have been proven as important tools for attracting young people. In his keynote speech called " 21 st Century Skills - From Industry to Education and Back" at 2010 NSF ATE Principal Investigator Conference, Mr. Charles Fadel, Global Education Research Lead at Cisco Systems, presented a study which indicates that students learn well in teams, in project based activities, and in collaborative environments. The hands-on project based activities will also strengthen students' skills in critical thinking, communication, collaboration, and creativity/innovation. These skills have been identified by top U.S. companies as priorities for employee development, talent management and succession planning [2]. It is only natural for the technology education to incorporate hands-on practical applications at every stage of a student's education. This connection should be made earlier during a student's high school years and be reinforced every semester during student's college years so as to allow the student to reach a level of maturity expected by companies for entry level or junior level positions.

In August 2010, the NYC College of Technology received a grant from National Science Foundation's 
Advanced Technology Education (ATE) division to establish a Mechatronics Technology Center (MTC) to introduce the mechatronics technology to college students in associate degree programs as well to high school students. NSF ATE supports innovative programs in associate degree institutions. The grant helped the college to produce more minority graduates in the areas of engineering technicians.

Our ATE project focuses on Integrated STEM Education using mechatronics products as vehicles to build student interest and to emphasize the intrinsic relations among various STEM fields. Robotics competitions held regularly at different levels enabled students to immerse themselves in STEM and to build their STEM skills gradually. This helped create, sustain, and foster long lasting interest on STEM. College students served as mentors to help faculty members conduct the training in various engineering topics as well as in learning the $21^{\text {st }}$ century skills [3-4].

\section{Technology Trend - Mechatronics Approach}

Advances in computer technology and semiconductor electronics have created a new product design field called mechatronics. Mechatronics treats product design as system design that requires the tight integration of mechanical components, electrical/electronic systems, industrial design ideas, computer-control systems, embedded systems, and intelligent software into the product design and development processes [5-6]. Most of the products now being developed are mechatronics in nature. This concurrent engineering and mechatronics design approach, which emphasizes team collaboration, has become the new industry standard in product design and development. In the foreseeable future, it is a matter of time for the employers to require graduates to have experience in interdisciplinary fields such as mechatronics.

\section{Mechatronics Technology Center (MTC) - Platform for Hands-on Learning}

Any good product went through many cycles of improvement. Engineers and designers learned from past failures through iterative design process to gain insight on how ideas work or not. That is the nature of product design.

In the college environment, students are fed with knowledge but seldom provide opportunity for students to practice the knowledge to solve product design problems and to provide opportunity to learn from their mistakes.

MTC provided an environment and a platform for students to continuously work on improving their design project and in the process to gain valuable experience.

\section{Hands-on Training - Hallmark of Technology Training}

Hands-on knowledge and experience are a vital component in educating today's engineering technicians and design engineers. You don't trust an auto-mechanics to fix your car, if you know he doesn't have any practical hands-on experience or knowledge.

Hands-on knowledge gives students new meaning on how theory works and gives students new perspectives when applying the theory. To many students, this could be the only way for them to learn the theory. That's why researches have indicated that hands-on activities are useful tools to learn technology, to engage people in learning. All activities in the MTC are somewhat tied to hands-on projects of multidisciplinary nature.

\section{Undergraduate Research - Tied to Curricular and Extracurricular Activities}

Since its inception, MTC has been instrumental in creating opportunities for college students to engage in undergraduate research in mechatronics. Students have completed numerous projects. Some projects are part of the students course work. Majority of the projects are the results of extra-curricular research activities where students find time outside the classroom to engage in mechatronics 
research under the supervision of faculty members from multiple engineering technology departments.

\subsection{FlexBot and SpiderBot Design Projects}

In fall 2010, two months after receiving the NSF ATE grant, two student teams in the Mechatronics Technology Center (MTC), started working on two projects: FlexBot project and SpiderBot project. FlexBot has a unique chassis design, a flexible suspension system that allows the robot to navigate on rough terrain. The camera mounted on the robot can relay the information to the control center. The SpiderBot is equipped with four suction cups. Each suction cup is capable to carry over 150 pound of weight. The Spider is designed to climb vertical surfaces. Both teams submitted their work to the Robotics Innovative Competition and Conference (RICC), a program run by WPI. Both were accepted as the top semi-finalists to participate in 2011 RICC held in Woburn, MA on April 10 $0^{\text {th }}, 2011$. Figure 1 and 2 are the two robot photos taken at the 2011 RICC.

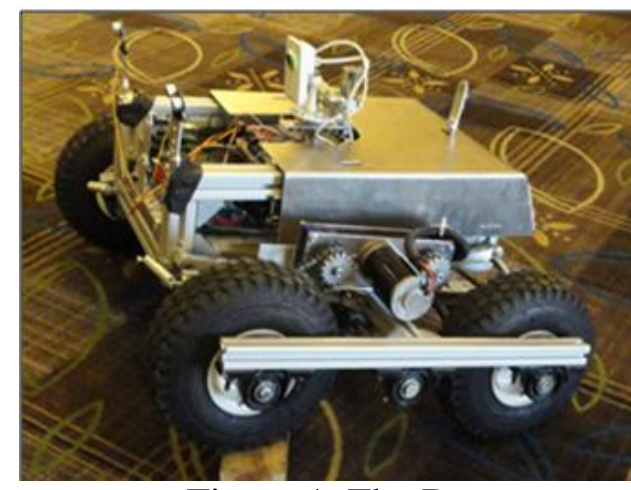

Figure 1. FlexBot

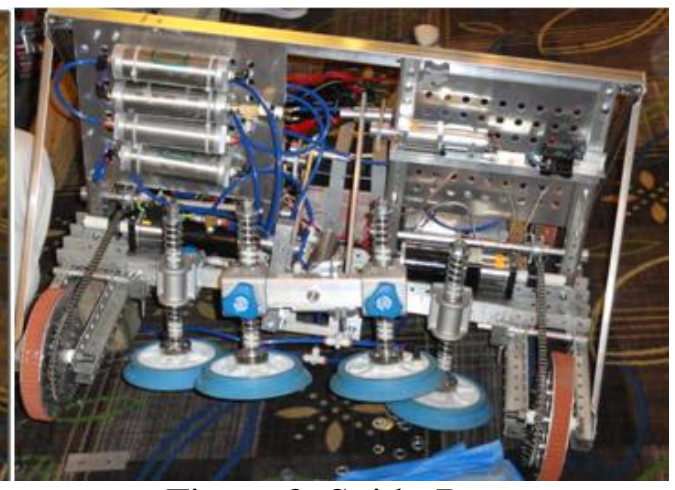

Figure 2. SpiderBot

\subsection{SniffBot Design Project for 2011ASME ISHOW}

Figure 3 is a chemical detection robot called SniffBot which is another robot that students at the MTC built. The SniffBot was equipped with chemical sensors that can detect different types of chemicals. The solar panel tilting mechanism mounted on the SniffBot can tilt the solar panel towards the light source automatically. The SniffBot was selected as one of the top ten semifinalists to participate in 2011 ASME Innovation Showcase (ISHOW) held Dallas, Texas on June 11, 2011. The SniffBot weighs over 120 pounds.

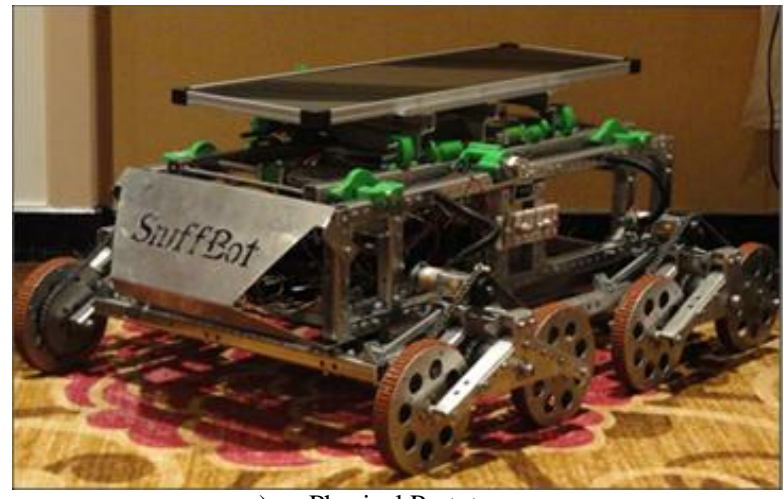

a) Physical Prototype

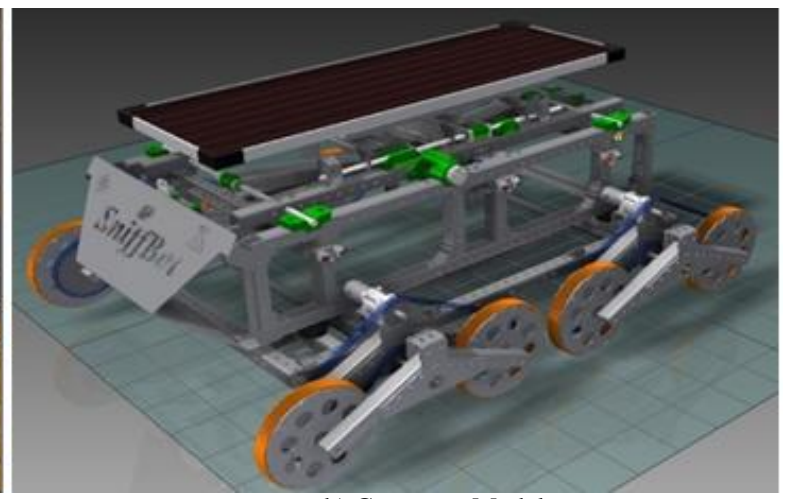

b) Computer Model

Figure 3. Large Chemical Detection Robot, SniffBot 


\subsection{Chemical Detection Robot Design Project in the Classroom}

A smaller version of a chemical detection robot called Sniffpuppy, which weighed about 15 pounds, is developed for students who are taking MECH 2410 - Machine Design in the Mechanical Engineering Technology department and EMT 2461 - Electromechanical Systems Software Interface in the Computer Engineering Technology department. Students from the two engineering technology departments collaborate in classes to design a small mobile chemical detection robot (CDR) that can be used to detect chemicals. The project consists of three major components: mechanical design, electrical/electronic design, and software design. Figure 4 shows one design of the CDR.

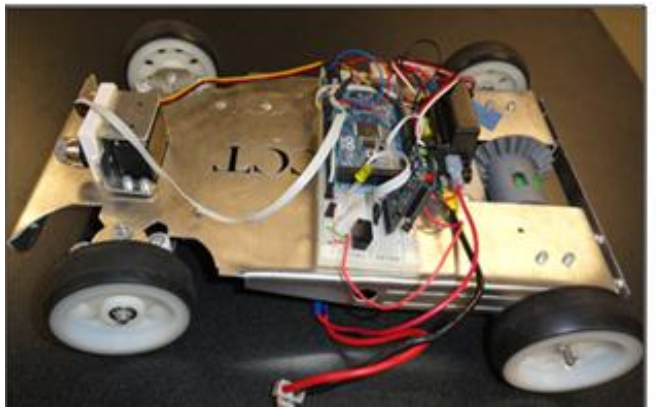

a) Physical Prototype

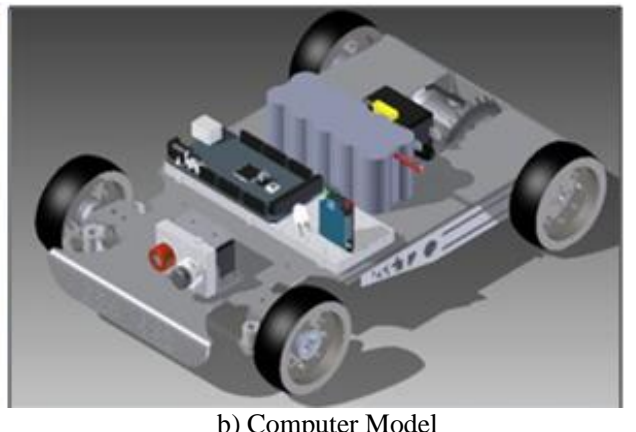

b) Computer Model

Figure 4. Small Chemical Detection Robot (CDR), Sniffpuppy

\subsection{Apple Collecting Robot Design Project}

In fall 2012, students in MECH 2410 and EMT 2461 collaborated again to design robots that can be used to collect up to 12 apples on the floor and put them into a basket. Figures 5 and 6 show two of students' designs work. The first one as shown in Figure 5 utilizes Arduino microcontroller to control the robot. The second one as shown in figure 6 uses the Lego Mindstorm's NXT brick as the robot controller.

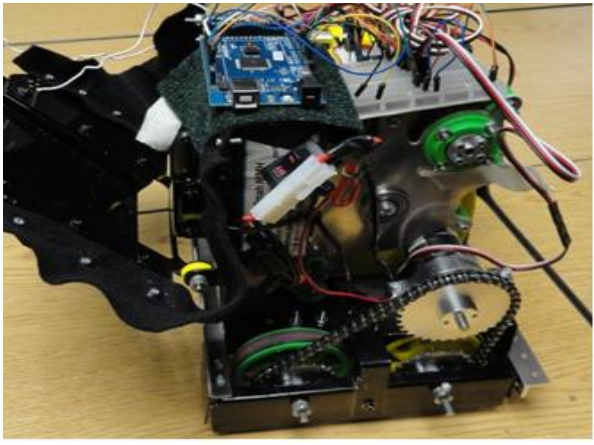

a) Physical Prototype

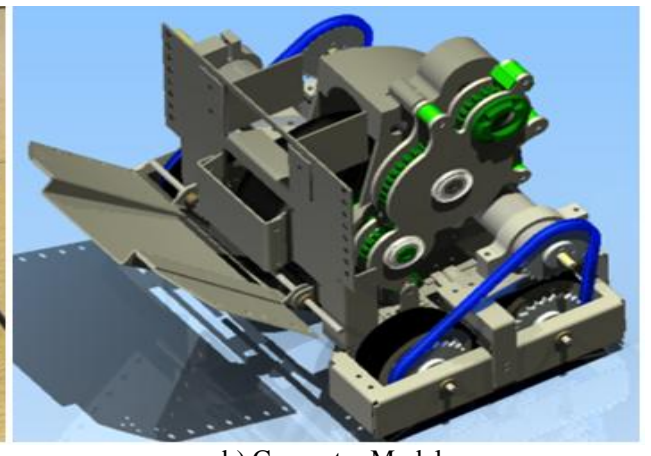

b) Computer Model

Figure 5. Apple Picking Robot, Design I

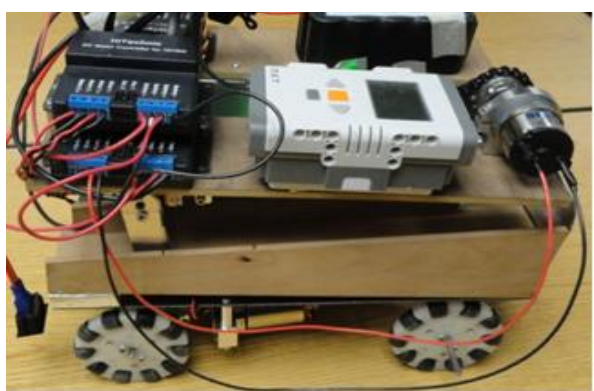

a) Physical Prototype

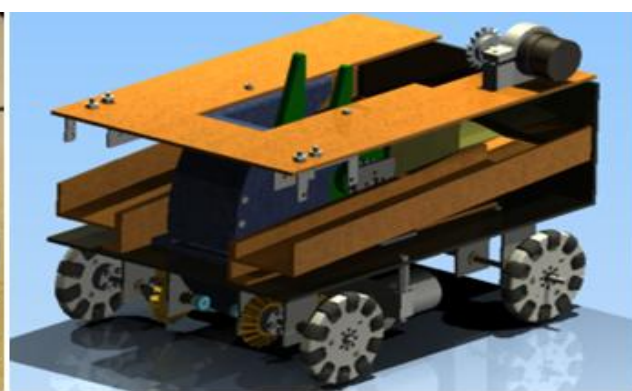

b) Computer Model

Figure 6. Apple Picking Robot, Design II 


\subsection{Endoscope Loop Detection Projects}

Two teams from MTC, one called Loop-O-Scope team and the other called Rare Loop Finder team, participated in 2012 American Society for Engineering Education (ASEE) Design and Manufacturing Competition held in San Antonio, TX, on June 12, 2012. The goal for the competition was to design and manufacture a device that could be used to detect the formation of a loop by endoscope tubing inside a patient's body and warn the doctors performing an upper endoscopy procedure.

The teams had only two month to design, test, and fabricate the devices for the competition. Both teams did an excellent job in presenting their devices at the competition, demonstrating outstanding professionalism, teamwork and enthusiasm. The Loop-O-Scope team used stretch sensors embedded into the endoscope to detect the formation of the loop, while the Rare Loop Finder team used fiber optics to detect the loop's formation. In the end, the Rare Loop Finder team won the placed third in the competition. Figure 7 shows the design using stretch sensors.

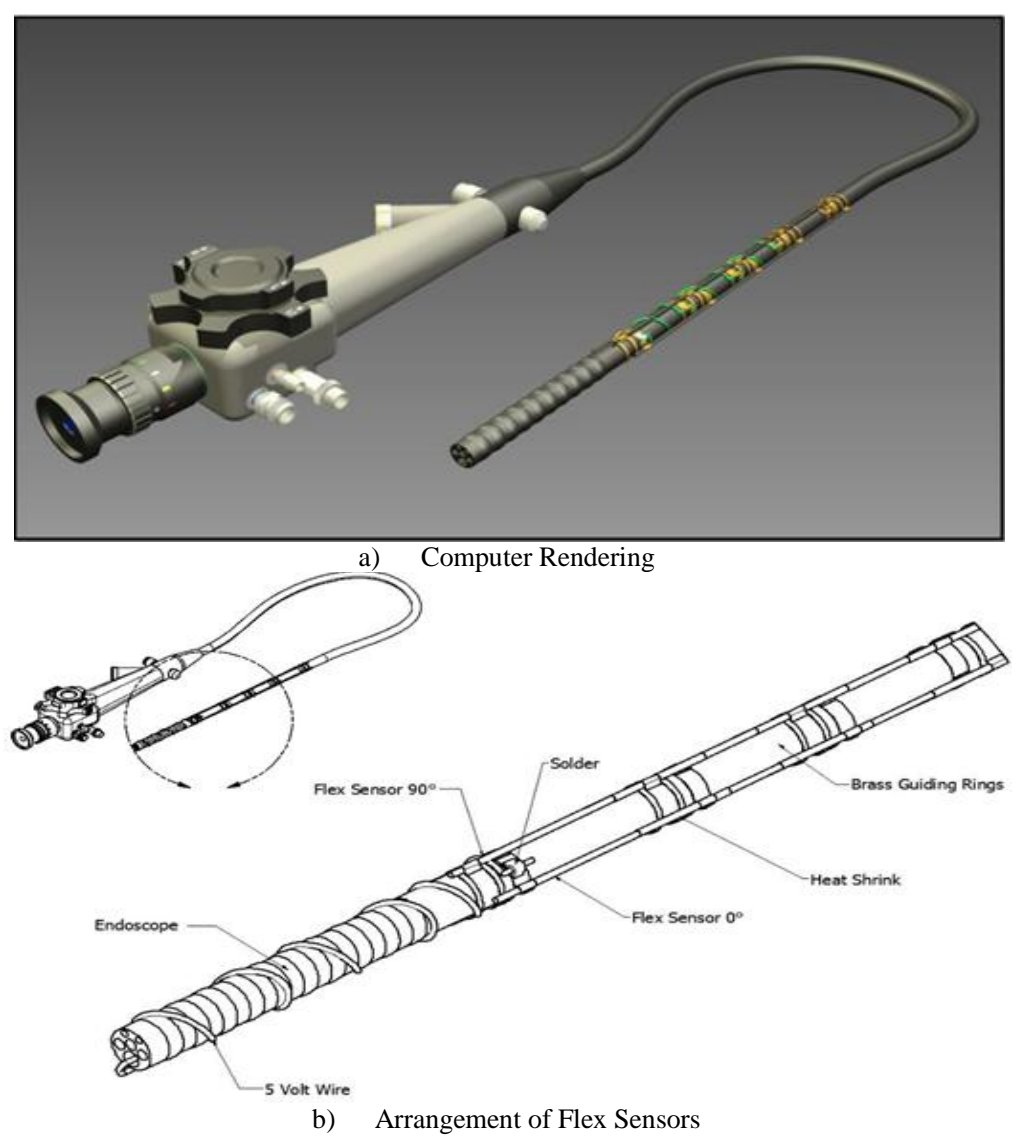

Figure 7. Endoscope Detection Device Using Flex (Stretch) Sensors

\subsection{Mobile Handheld Chemical Detection Device (HCDD) Project}

Faculty members also worked with outside partners with the help of MTC students to develop products that address issues such as environmental concerns. One of the joint venture projects is the design of a handheld chemical detection device called AirCasting device. This device can detect harmful and lethal chemical gases $\left(\mathrm{NO}_{2}, \mathrm{~N}_{2}, \mathrm{CO}, \mathrm{CO}_{2}, \mathrm{LPG}, \mathrm{CH}_{4}, \mathrm{CNG}, \mathrm{C}_{2} \mathrm{H}_{5} \mathrm{OH}, \mathrm{NH}_{3}\right.$, $\mathrm{H}_{2}$ and others) in the public and in private gathering places. This mobile handheld device then can relay the information detected to smart phones or tablets or laptops in any place at any time. 
Applications of this useful mobile device include coal mine explosion prevention, detections of natural gas and other industrial and explosive chemical leaks, and detection of harmful gases in the public gathering places such as subway stations, shopping malls, and airports. Figure 8 shows a prototype of the handheld device.

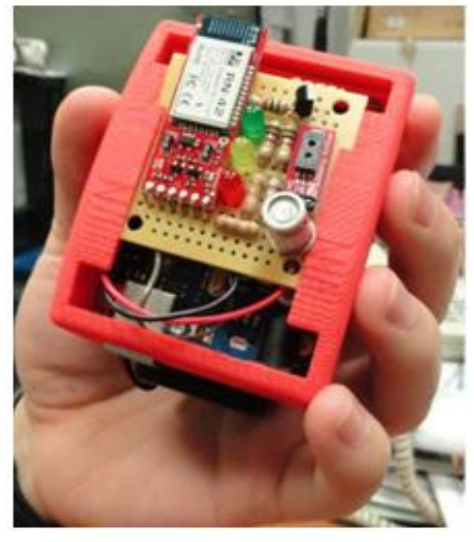

a) Prototype of HCDD
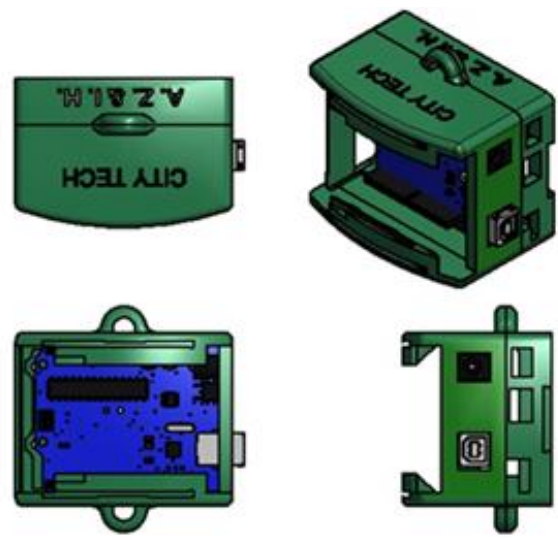

b) Case Design

Figure 8. Mobile Handheld Chemical Detection Device

As can be seen, the scope of all the design projects reflected interdisciplinary nature of product design and development. It requires the students from different departments to really work as a team to complete these projects. The experience gained from these activities is quite different from what they have learned in the past. Students from the two departments collaborated with each other and gained important experience in team work, time management, and collaboration and cooperation through these design activities. This could not have happened under the traditional classroom lecture or traditional lab experiment setting.

\section{Outreach Efforts}

Our outreach efforts focused on using robotic technology to encourage middle and high school students to study STEM. We provided support to many existing Pre-engineering programs such as FIRST Robotic Competition (FRC), FIRST Tech Challenge (FTC), and Science and Technology Entry Program (STEP).

\subsection{Working with FRC Teams}

Besides offering workshops to many local high schools' FRC teams, in January 2012, we started sponsoring two Rookie FRC teams to build robots in the Mechatronics Technology Center at the College. College students serve as mentors to help two rookie teams to build their robots for the annual FIRST Robotic Competition which is held in March every year. Figure 9 is one of the robots that college students helped to build for one rookie team.

To maximize participation, the trainings were offered on weekends in conjunction with our FIRST partners, in afterschool programs, and in summer programs. Weekend classes make it possible for interested students, their parents, and high school teachers to attend. Training modules include: robotic programming, mechanical principles and design, electrical/electronic principles and design, and solid modeling using 3D computer design software such as Autodesk Inventor and PTC's Creo Elements/Pro. Students of Over 30 high schools were exposed to the various elements of STEM through the hands-on projects. 


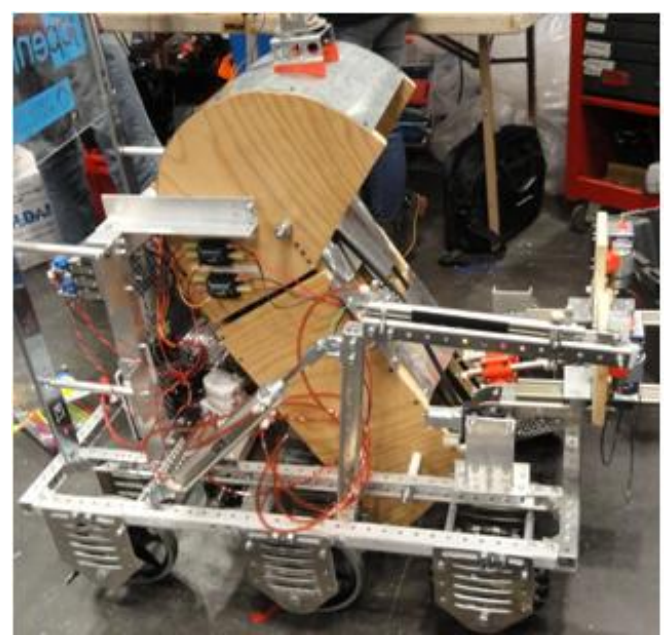

Figure 9. Robot built by a Rookie Team

\subsection{Working with FTC Teams}

FIRST Tech Challenge (FTC) is another division of FIRST. It allows high school students to build much smaller robots at an affordable cost. Mechatronics Technology Center (MTC) organized numerous workshops on programming, solid modeling, and mechanical design. Figure 10 is a photo taken at the end of 2012 Summer Robotic Camp.

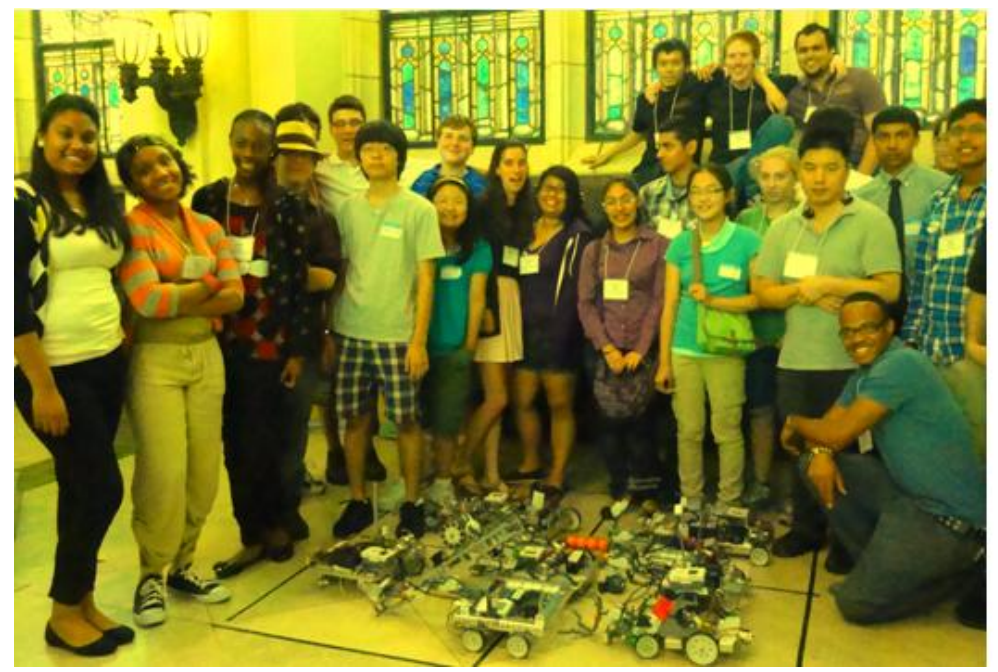

Figure 10. 2012 Summer Robotic Camp

\subsection{Working with STEP Team}

In 2012, faculty members and students from MTC started to work with the college's outreach division to help it to run a robotic project for the New York State's Science and Technology Entry Program (STEP), a program aimed at introducing high school students the wonders of STEM through robotics. High school students were required to build a small robot using Lego Mindstorm NXT 2.0 Robotic kit and participate in annual NYS STEP Robotic Competition. At the first NYS STEP Robotic Competition held in April 1 ${ }^{\text {st }}, 2012$ in Albany, New York, the high school team won the third place. Figure 11 shows the robot built by the team. 


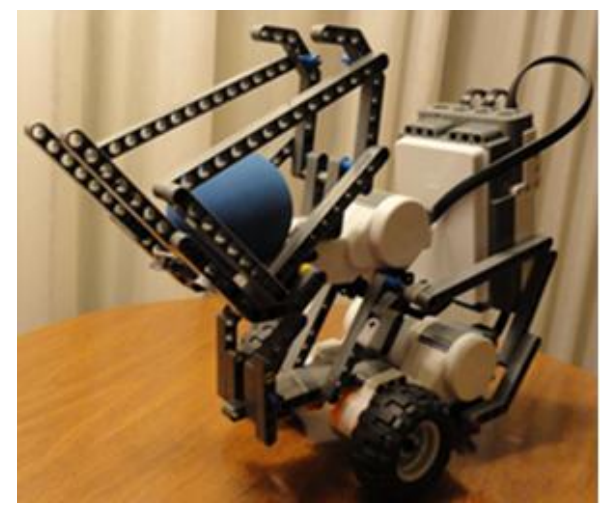

Figure 11. Robot Built for STEP.

\section{Other Promotional Activities}

Faculty members working in the MTC have published and presented the results of the hands-on project-based activities in over ten national and international conferences. Some of the works are in the process of being published in journals as well. Students working in the MTC have been very active in promoting the benefits of hands-on mechatronics activities. Over the past two years, students have been instrumental in helping the faculty members to organize numerous training events and educational tours on robotics and mechatronics to middle school, high school, and college and university students. One of the events is shown in Figure 12. On which a MTC student was showing to a group of college students and faculty members from other campuses, and to senior ASME members who endoscope detecting device works.

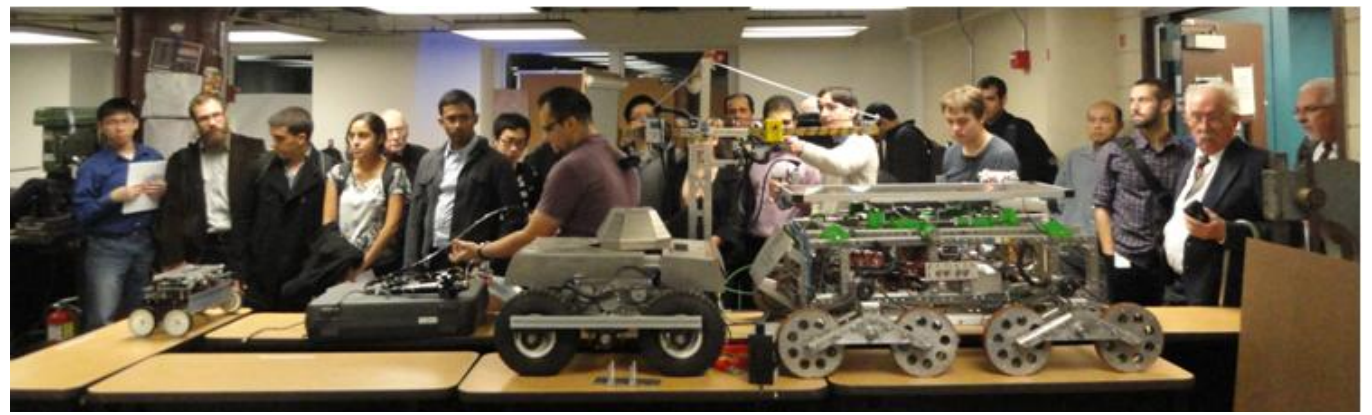

Figure 12. A Visit to Mechatronics Technology Center

Figure 13 shows MTC students promoting Mechatronics Technology at 2012 New York Maker Faire. Over 45000 people attended the 2012 New York Maker Faire. The college received the educator's choice award the attracting many audiences.
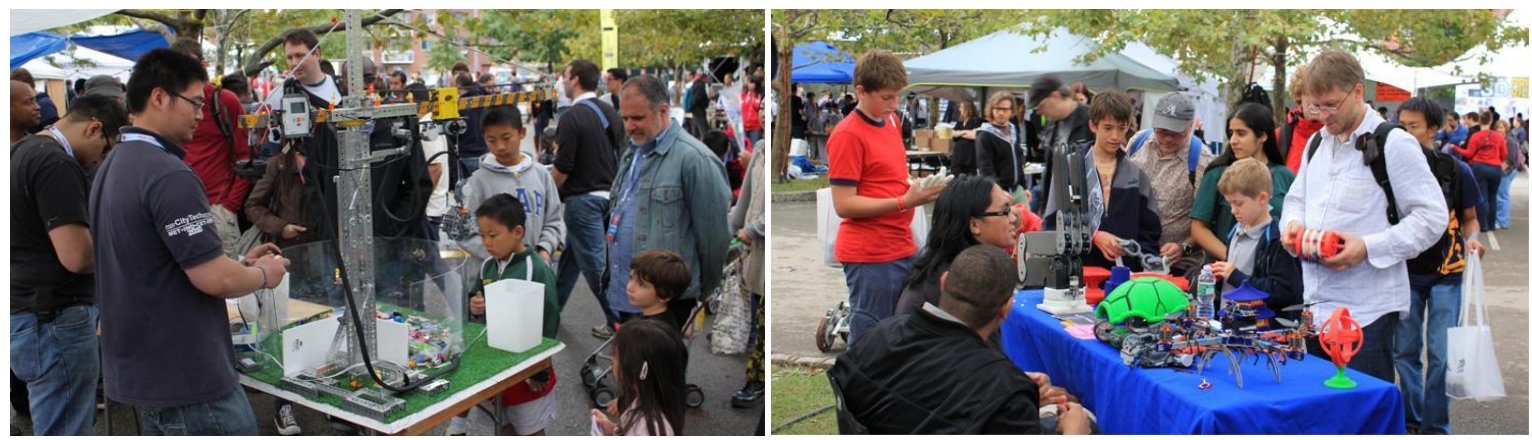

Figure 13. MTC students at the 2012 New York Maker Faire 


\section{Conclusions}

Hands-on project-based multidisciplinary design projects attract students' interest and motivate them to learn more. Since we established the MTC in fall 2012, over 60 students signed up to join the Mechatronics Club. Over 200 college students were exposed the mechatronics technology through participating in various hands-on projects.

It takes time for students to gain insight on mechatronics product design. This requires or forces students to go beyond their specific disciplines and gain knowledge in other areas in order to collaborate and communicate with students from other disciplinary fields. We have noticed the students who have stayed with the program for more than two years have transformed them into much better thinkers and designers. These hands-on projects also strengthened students' skills in critical thinking, communication, collaboration, and creativity/innovation.

It is only natural for the technology education to incorporate hands-on practical applications at every stage of a student's education. This connection should be made earlier during a student's high school years and be reinforced every semester during student's college years so as to allow the student to reach a level of maturity expected by companies for entry level or junior level positions.

\section{Acknowledgements}

The work is funded by a grant from the National Science Foundation (NSF) Advanced Technological Education (ATE) Division. The award number is DUE \#1003712. The authors greatly appreciate the support from the NSF. The authors would also like to thank the students for participating in various mechatronics design and competition activities.

\section{References}

[1] Beering, Steven C. 2009. "National Science Board STEM Education Recommendations for the President-Elect Obama Administration" National Science Board, NSB-09-1 January 11.

[2] Fadel, Charles. 2010. "21st Century Skills - From Industry to Education and Back" October 26-28, NSF ATE Principal Investigator Conference.

[3] Bellanca, James and Brandt, Ron. (2010). " $21^{\text {st }}$ Century Skills - Rethinking How Students Learn" Solution Tree Press, 2010, ISBN 978-1-935249-90-0.

[4] Thomas, Douglas and Brown, John Seely. (2011). "A New Culture of Learning - Cultivating the Imagination for a World of Constant Change”, ISBN-13 978-1456458881, ISBN-10 145658884.

[5] David G. Alciatore and Michael B. Histand, "Introduction to Mechatronics and Measurement Systems", Third Edition, McGraw-Hill Company, 2007.

[6] W. Bolton, "Mechatronics - Electronic control Systems in Mechanical and Electrical". $4^{\text {th }}$ Edition, Prentice Hall, 2008. 